\title{
Penggunaan Prinsip Fengsui dalam Penentukan Ruang Ibadah Pada Wihara Pemancar Keselamatan Kota Cirebon
}

\author{
Tecky Hendrarto, Ramadhan Rachmatuloh, Mochamad Ridwan Arif A., \\ Tazkiya Savarani, Marzuq Fakhri Abdul Aziz \\ Jurusan Arsitektur, Fakultas Teknik Sipil dan Perencanaan, Itenas, Bandung \\ email: tecky@itenas.ac.id
}

\begin{abstract}
ABSTRAK
Proses peribadahan di wihara memiliki tata cara serta alur ibadah dalam berdoa. Urutan tata cara ibadah mempengaruhi posisi ruang ibadah di dalam wihara. Letak dan urutan para Dewa yang harus disembah oleh jemaah secara berurutan didasarkan dari kedudukan para Dewa. Letak ruang ibadah akan berpengaruh terhadap alur ibadah jemaah. Selain memperhatikan hierarki dan posisi dewa di ruang ibadah, orientasi wihara pun harus sesuai dengan fengsui agar menghadirkan energi postif yang dipercaya dapat mengundang nasib baik. Kajian ini bertujuan untuk mengetahui bagaimana penggunaan fengsui pada hierarki ruang ibadah wihara. Lingkup studi pada kajian ini penggunaan fengsui pada penempatan Dewa pada ruangan dan pada penempatan ruang di wihara beserta orientasinya. Metode analisis yang digunakan adalah metode kualitatif. Hasil dari penelitian ini menunjukkan bahwa, fengsui mempengaruhi penentuan hierarki ruang tata letak, dan orientasi Wihara Pemancar Keselamatan, contohnya dewa yang memiliki hierarki tertinggi berada di tengah dan terdalam ruangan, diikuti pada dewa yang letaknya di bagian kiri kemudian kanan, karena bagian kiri lebih utama daripada kanan. Kemudian, semakin jauh ruangan dari gerbang depan, maka semakin tinggi pula tingkat kesakralan ruangan tersebut. Letak Wihara Pemancar Keselamatan menghadap ke sumber air, yaitu sungai dan berada di posisi tusuk sate yang berfungsi untuk menyerap energi buruk agar energi tersebut tidak membawa nasib buruk kepada masyarakat di sekitar.
\end{abstract}

Kata Kunci: Wihara, Hierarki Ruang Ibadah, Orientasi

\begin{abstract}
In the process of worship in temple, there are certain procedures and flows. There is a certain sequence of gods that must be worshiped. The sequence is based on the hierarchy of the gods within the temple. The sequence certainly affected the position of the worship halls in the temple. The position of the worship halls will affect the flow of worship services. In addition to paying attention to the hierarchy and position of the god in the worship halls, the orientation of the temple must be in accordance with Feng Shui in order to present positive energy that is believed to invite good fortune. This study aims to find the usage of Feng Shui in the temple's worship halls hierarchy. The scope of the study is the usage of Feng Shui to determine the deity of the room and the layout of the temple and its orientation. The analytical method used is a qualitative method. The results of this study indicate that Feng Shui influences the hierarchy of layout, and orientation of the Wihara Pemancar Keselamatan, for example the god who has the highest hierarchy is in the middle and deepest of the hall, followed by the god located on the left and the right respectively, because the left is more honorable than right. Then, the farther the room from the front gate, the higher the level of sacredness of the hall. The location of Wihara Pemancar Keselamatan faces the water source, the river and is in the position of a Tuction which serves to absorb bad energy so that the energy does not bring bad luck to its surrounding.
\end{abstract}

Keywords: Temple, Hierarchy of Worship Halls, Orientation 


\section{PENDAHULUAN}

Fengsui adalah ilmu topografi kuno dari Tiongkok yang mempercayai hubungan harmoni antara manusia dengan surga (astronomi) dan bumi (geografi) dapat memperbaiki kehidupan dengan menerima Chi positif, energi positif. Chi positif dapat membawa nasib baik, sedangkan Chi buruk akan membawa nasib buruk. Fengsui biasa digunakan untuk mengatur letak bangunan seperti rumah, kantor, dan toko, selain itu digunakan juga untuk mengatur tata kota, kuburan dan tidak terkecuali tempat ibadah.

Wihara Pemancar Keselamatan atau Kelenteng Boen San Tong berlokasi di sebelah barat Pasar Kanoman. Wihara ini merupakan tempat peribadahan umat Buddha, yang diperkirakan berdiri pada 1894 M. Pada tahun 1996, dilakukan perluasan di bagian belakang wihara.

Pada proses peribadahan di dalam wihara, terdapat tata cara dan alur tertentu dalam berdoa. Ada posisi dan urutan dewa-dewa yang harus sembah oleh jemaah secara beraturan. Urutan tersebut didasarkan pada kedudukan dewa-dewa yang ada di wihara. Urutan ibadah ini tentunya mempengaruhi posisi ruang ibadah di wihara. Posisi ruang ibadah akan berpengaruh terhadap alur ibadah jemaah. Selain memperhatikan hierarki dan posisi dewa di ruang ibadah, orientasi wihara pun harus sesuai dengan fengsui agar menghadirkan Chi postif yang dipercaya dapat mengundang nasib baik.

Kesesuaian antara hierarki ruang dan orientasi bangunan Wihara Pemancar Keselamatan dengan teori fengsui sangat penting, karena berhubungan dengan kepercayaan masyarakat Cina yang merupakan jemaah Wihara Pemancar Keselamatan.

Permasalahan yang akan dibahas dalam kajian ini adalah: a) pengaruh fengsui terhadap hierarki ruang Wihara Pemancar Keselamatan, dan b) pengaruh fengsui terhadap orientasi tata massa bangunan Wihara Pemancar Keselamatan.

Metode penelitian yang digunakan adalah metode gabungan antara metode kualitatif yaitu dengan mengolah data-data yang diperoleh dari observasi langsung ke objek penelitian dan wawancara di lapangan, dan metode deskriptif yaitu dengan riset kepustakaan berupa studi literatur dan media informasi yang berhubungan dengan pembahasan dan menggunakan objek penelitian adalah Wihara Pemancar Keselamatan.

\section{TINJAUAN UMUM}

\subsection{Fengsui}

Fengsui adalah seni geomansi ${ }^{1}$ Cina, berupa proses pemilihan lahan rumah dan kuburan yang baik berserta konstruksi yang tepat. Fengsui berasal dari gabungan dua kata yaitu, feng (風) berarti angin dan shui (水) berarti air atau sungai. Sehingga, secara harfiah fengsui berarti angin dan air, dan dapat disimpulkan bahwa menentukan baik tidaknya sebuah lahan dapat dilihat dari keadaan alam disekitarnya. Fengsui berkembang agar manusia dapat hidup harmonis dengan alam di sekitarnya.

Fungsi dari fengsui ialah agar manusia dapat hidup harmonis dengan alam disekitarnya. Bangunan yang dibangun dapat menghadirkan kenyamanan secara fisik maupun spiritual. Bagi pengguna fengsui, bangunan yang didirikan akan mendatangkan kemakmuran, kebahagiaan, kedudukan/jabatan,

\footnotetext{
${ }^{1}$ ilmu meramal berdasarkan pengamatan pada garis-garis atau gambar-gambar (KBBI).
} 
panjang umur dan keturunan bagi penggunanya. Sedangkan untuk kuburan yang dibuat berdasarkan petunjuk fengsui akan memberikan perlindungan bagi keturunannya.[1]

\subsection{Implementasi Fengsui}

Bagi masyarakat etnis Cina, peletakan massa bangunan yang paling baik adalah berada pada arah Selatan. Hal tersebut dikarenakan banyaknya intensitas cahaya matahari yang akan diterima. Berdasarkan keadaan geografi di Cina, wilayah selatan adalah wilayah yang beriklim paling nyaman dan hangat, sehingga menjadi sumber yang dianggap baik. Sebaliknya, wilayah utara merupakan wilayah yang kurang menguntungkan, karena merupakan daerah gurun dan dianggap gelap dan menghembuskan angin dingin (feng). Dari dasar teori tersebut, bangunan-bangunan penting di Cina seperti istana dan rumah ibadah menghadap ke arah Selatan.[2]

Dalam penerapan peletakan bangunan klenteng atau wihara berorientasi pada letak laut ataupun sungai. Ahli Fengsui yang menganut aliran bentuk akan menentukan lokasi yang dianggapnya menguntungkan dengan memulai langkah kerjanya melalui pencarian naga. Penekanan aliran ini adalah pada bentuk tanah, bentuk lembah, dan gunung, saluran air, serta orientasi dan arahnya.[5] Dalam istilah fengsui, naga diwakili oleh bentuk tanah tinggi sebagai perwujudan simbol tersebut. Peletakan klenteng atau wihara khususnya di Kota Cirebon ataupun kebanyakan kota di pesisir Utara pantai Jawa berorientasi menghadap Utara. Hal tersebut mengacu pada peletakkan bangunan yang mengahadap ke arah laut. Karena menurut fengsui arah yang baik adalah tempat yang dekat dengan sumber mata air, bukit-bukit, pegunungan, dan lembah di sekeliling bangunan, karena tempat-tempat tersebut memiliki energi vital yang baik.[2]

Pengaplikasian selanjutnya adalah mengenai tata letak bangunan yang berada pada area "tusuk sate", menurut pengertiannya bangunan tusuk sate merupakan bangunan yang posisinya terletak di tengah jalur pertigaan sebuah jalan. Menurut fengsui, lokasi "tusuk sate" harus dihindari sebagai tempat tinggal atau hunian, karena akan ada banyak masalah yang timbul pada penghuni bangunan tersebut. Bangunan yang terletak di area "tusuk sate" diyakini tidak membawa hoki dan penghuni akan menderita penyakit.[3]

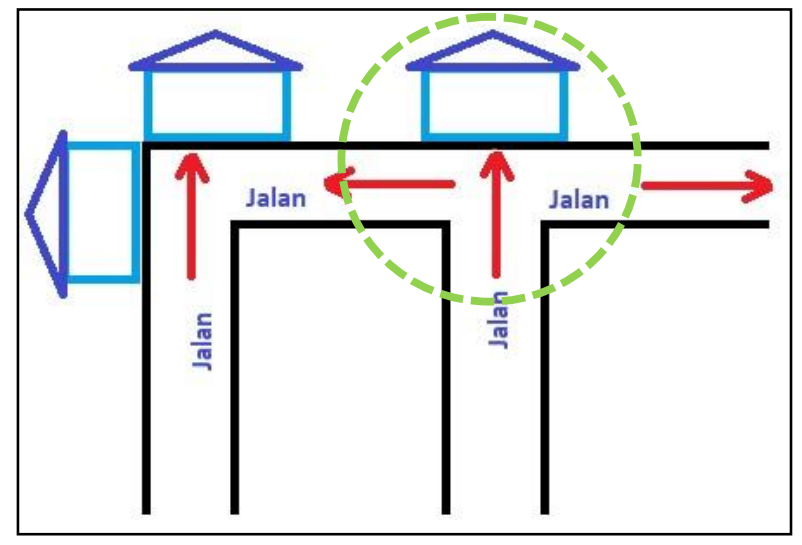

Gambar 2.1 Gambar ilustrasi bangunan tusuk sate Sumber: https://imam.web.id/pengertian-rumah-tusuksate-2018

Namun, dalam beberapa bangunan wihara atau klenteng dijumpai terletak di dalam area "tusuk sate". Keberadaan bangunan ini dapat dilihat seperti memotong salah satu jalur pertigaan sehingga nampak seperti jalan buntu. Penempatan wihara di posisi ini tentu memiliki beberapa alasan dan pertimbangan, salah satunya bertujuan untuk menyerap dan menetralkan sha ch $^{\prime} i^{2}$, sehingga masyarakat tidak terganggu kehidupannya.[2]

\footnotetext{
${ }^{2}$ Sha ch'i dalam Bahasa Cina berarti energi buruk.
} 
Menurut fengsui, lokasi yang baik adalah lokasi yang seimbang, antara perbedaan ketinggian lokasi dengan ketinggian jalan. Ketinggian maksimal suatu lahan dari permukaan jalan adalah $1-2$ meter. Pada posisi seperti ini terdapat keseimbangan yang tepat, sehingga terjadi ikatan yang harmonis antara jalan dengan lokasi bangunan. Dalam setiap bangunan klenteng hal ini selalu diterapkan, ketika memasuki bangunan selalu terdapat anak tangga yang memberikan perbedaan ketinggian lantai halaman dengan bangunan utama. Pemilihan lahan yang baik menurut fengsui adalah lahan berbentuk kantong tertutup. Lahan berbentuk kantong tertutup adalah lahan yang melebar di bagian belakang. Artinya, lahan tersebut memiliki sisi belakang yang lebih panjang dibandingkan dengan sisi depannya. Bentuk lahan seperti ini akan mendatangkan hoki dan dipercaya penghuninya dapat menyimpan harta berlimpah.[3]
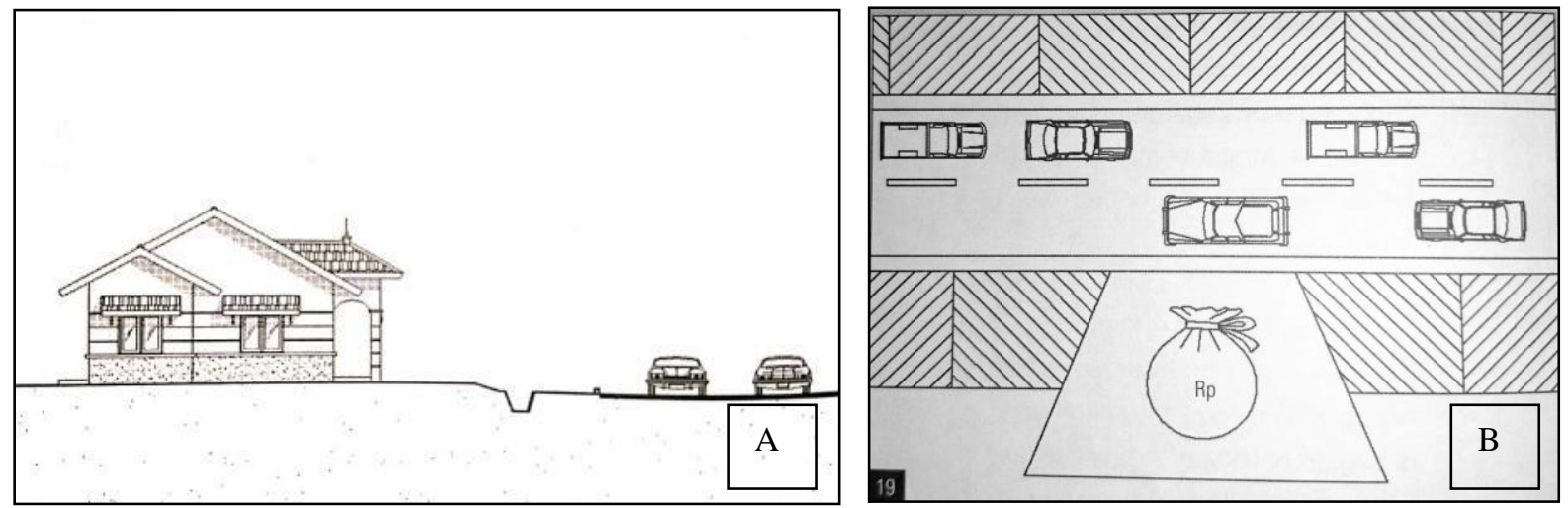

Gambar 2.2 (A) Lokasi Bangunan dan Jalan Seimbang; (B) Lahan bentuk Kantong Tertutup Sumber: Buku Rumah Hoki: Menurut Pandangan Feng Shui dan Arsitektur

Pintu kelenteng teridiri dari satu panil yang berdaun ganda menyebabkan $c h$ ' $i$ (energi) bisa masuk dan bersirkulasi secara leluasa. Pintu ganda melambangkan keseimbangan. Pilar-pilar di dalam ruangan adalah pilar bulat untuk menghindari seng $c h{ }^{\prime} i{ }^{3}$ terpecah menjadi sha $c h ' i$. Altar pemujaan untuk dewa-dewi yang berada di dalam bangunan juga mengikuti aturan fengsui. Altar dewa utama ditempatkan di tengah ruangan, sedangkan untuk dewa-dewi yang lain ditempatkan pada sisi kiri dan kanan altar utama. Altar tempat pemujaan Kwan Sie Im ditempatkan di sisi "naga" yang melambangkan sebagai penghormatan. Selanjutnya kelebihan ruang di sisi kanan dan kiri ruang utama difungsikan sebagai tempat penyimpanan barang dan keperluan pendukung kegiatan ibadah.[2]

\subsection{Hierarki Ruang Ibadah di Wihara}

Wihara, menurut Kamus Besar Bahasa Indonesia (KBBI) adalah biara yang didiami oleh para biksu. Kelenteng adalah rumah ibadah penganut taoisme, maupun konfucuisme (konghucu). Kelenteng dan wihara pada dasarnya berbeda dalam segi arsitektur, umat dan fungsi. Wihara merupakan tempat ibadah untuk umat Buddha. Wihara umumnya tidak memiliki banyak rupang/patung, hanya ada patung Budha atau patung Dewi Kwan She Im. Sedangkan kelenteng pada dasarnya berarsitektur tradisional Tionghoa dan berfungsi sebagai tempat aktivitas sosial masyarakat, selain berfungsi sebagai tempat spiritual. Di dalam Kelenteng terdapat berbagai macam rupang/patung dewa-dewi, diantaranya rupang aliran Buddha Mahayana, rupang aliran Taois, rupang aliran Konfusianis ${ }^{4}$. [4]

Tabel 1. Perbedaan Wihara dan Klenteng

\begin{tabular}{ccc}
\hline No. & Wihara & Klenteng \\
\hline 1 & $\begin{array}{c}\text { Rumah ibadah umat Ubddha, bisa juga } \\
\text { dinamakan kuil. (Wikipedia.id) }\end{array}$ & $\begin{array}{c}\text { Rumah ibadah penganut taoisme, maupun } \\
\text { konfucuisme (konghucu). (Wikipedia.id) }\end{array}$ \\
\hline 2 & Tidak memiliki banyak rupang/patung, & Terdapat berbagai macam rupang/ patung dewa \\
\hline
\end{tabular}

\footnotetext{
${ }^{3}$ Seng ch'i menurut Bahasa Cina berarti energi baik.

${ }^{4}$ Di Indonesia biasa dikenal dengan Konghucu.
} 


\begin{tabular}{|c|c|c|}
\hline & $\begin{array}{c}\text { hanya ada patung Budha atau patung Dewi } \\
\text { Kwan She Im. }\end{array}$ & $\begin{array}{l}\text { - dewi, diantaranya rupang aliran Buddha } \\
\text { Mahayana, rupang aliran Taois, rupang aliran } \\
\text { Konfusianis. }\end{array}$ \\
\hline 3 & $\begin{array}{c}\text { Merupakan tempat ibadah untuk umat } \\
\text { Budha. }\end{array}$ & Berarsitektur tradisional Tionghoa. \\
\hline
\end{tabular}

Hierarki merupakan salah satu unsur terpenting pada kelenteng dan bangunan Cina pada umumnya. Hierarki biasanya berupa urutan mengenai peletakan area yang paling suci (biasanya altar leluhur). Di istana kerajaan, sumbu hierarkinya ditentukan dengan peletakan pintu gerbang mengarah dari utara selatan. Semakin suci dan tinggi derajat sebuah ruang, peletakannya akan semakin jauh dari pintu utama, semakin kearah selatan.[2]

Dalam budaya Tionghoa, kiri lebih diutamakan dari kanan. Ketika melangkah masuk ruang sembahyang juga harus kaki kiri terlebih dahulu yang maknanya adalah kita harus mengutamakan sifat-sifat kebajikan kita. Menancapkan Hio dengan tangan kiri juga artinya kita akan selalu manancapkan kebajikan di alam langit dan bumi.

Pada waktu bersembahyang di kelenteng, terlebih dahulu bersembahyang kepada Tian, Sam Kuan Tai Te, dan lain-lain dengan menghadap keluar, selanjutnya menghadap ke arah dalam kelenteng untuk bersembahyang ke Kongco/Maco tuan rumah. Altar dari Kongco/Maco tuan rumah berada di tengah bagian belakang ruang utama kelenteng. Setelah bersembahyang ke Kongco/Maco selanjutnya menuju altar dari Budha yang berada disebelah kiri dari Kongco/Maco tuan rumah. Tahapan selanjutnya menuju altar dari Dewi Kuan She Im dan mengelilingi altar (bersembahyang) dari sisi kiri menuju kanan. Apabila sebuah kelenteng memiliki sayap pada bangunannya maka harus bersembahyang dari sayap kiri ke sayap kanan.

Secara hakiki, dasar kepercayaan orang Tionghoa yang kemudian diperkuat oleh ajaran Kong Zi disebut Jing Tian Zun Zu yaitu "mengagungkan langit (Tuhan) dan menghormati leluhur". Kemudian, dasar kepercayaan tersebut, diperkaya dengan ajaran Kofusianisme, Toisme dan Buddhisme. Pergabungan ini disebut $\mathrm{Zu}$ Xian Jiao (agama leluhur). Agama inilah yang sekarang dianut oleh sebagian besar orang Tionghoa baik di negeri asalnya maupun di perantauan.

Sirkulasi umat dalam ruang ibadah memiliki dua versi dimensi hierarki, yaitu:

1. Hierarki kekeluargaan menurut konfusius (family lineage).

Menurut konsep kekeluargaan konfusius, zoning ruang terdalam adalah untuk warga tertua (senior), dan yang muda di bagian muka. Ruang di sayap kiri dan kanan untuk yang lebih muda dalam status hierarkinya dari penghuni bangunan utama.[6]

2. Hierarki menurut mitologi kepercayaan popular masyarakat.

Sedangkan hierarki menurut kepercayaan popular masyarakat adalah mengikuti hierarki pejabat kekaisaran, rupang/patung tuan rumah di titik sumbu terdalam, disebelah kirinya rupang tokoh sipil berstatus primer, di kanan tuan rumah berstatus sekunder atau tokoh militer. Posisi penempatan rupang/patung di ruang sayap kiri berstatus lebih tinggi dari pada di ruang sayap kanan. Ruangan di bangunan sayap ke arah muka bangunan berstatus lebih rendah daripada yang di dalam.[6]

\subsection{Wihara Pemancar Keselamatan}

Wihara Pemancar Keselamatan, atau Kelenteng Boen San Tong adalah salah satu Bangunan Cagar Budaya Kota Cirebon setelah dikeluarkannya Surat Keputusan Walikota Cirebon Nomor 19 tahun 2001. Bangunan yang terletak di Jalan Winaon No. 69/26 Kelurahan Pekalipan, Kecamatan Kanoman Utara ini, merupakan sebuah Wihara yang diperkirakan dibangun pada tahun $1894 \mathrm{M}$ dan mengalami renovasi di tahun 1996. Belum ada penuturan jelas mengenai tanggal tepatnya dan pendirinya. Saat ini Wihara Pemancar Keselamatan berada di bawah naungan Yayasan Pemancar Keselamatan sebagai pengurus wihara. 
Wihara Pemancar Keselamatan merupakan tempat ibadah umat Buddha. Hal yang menandakan bahwa wihara ini memiliki jemaah Buddha adalah dengan adanya patung Buddha pada sisi kiri wihara dan patung Dewi Kwan Im sebagai penjelmaan Dewi Welas Asih. Selain sebagai tempat ibadah umat Buddha, Wihara Pemancar Keselamatan juga menjadi tempat digelarnya rangkaian perayaan Imlek karena sebagian besar umat Buddha di tempat ini juga merupakan keturunan Tionghoa.

Dari segi langgam arsitektural bangunan ini tidak berbeda jauh dengan wihara pada umumnya. Memiliki ornamen lampion, guci, serta banyak ukiran hewan mitologi China. Wihara ini memiliki warna dasar bangunan merah dan emas yang merupakan lambang keberuntungan dan kemewahan. Bentuk dan desain ruangan pada ruang ibadah depan sangat khas dengan atap melengkung dan tiangtiang kayu sebagai penyangga.

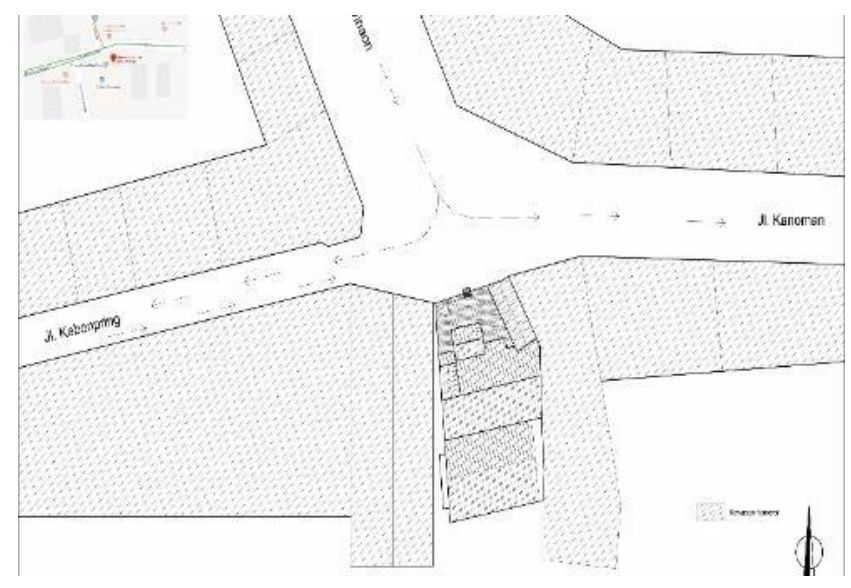

Gambar 2.3 Block Plan Wihara Pemancar

Keselamatan

(Sumber: Data survey lapangan tanggal 1 Maret 2019)

Wihara Pemancar Keselamatan terletak di persimpangan antara Jalan Winaon dan Jalan Kanoman.

Bangunan berbentuk memanjang (linier). Menurut fengsui bangunan ini berada di persimpangan jalan berbentuk "T" yang menandakan lokasi "tusuk sate". Lokasi tersebut bertujuan untuk menyerap energi negatif dari bangunan disekitarnya.
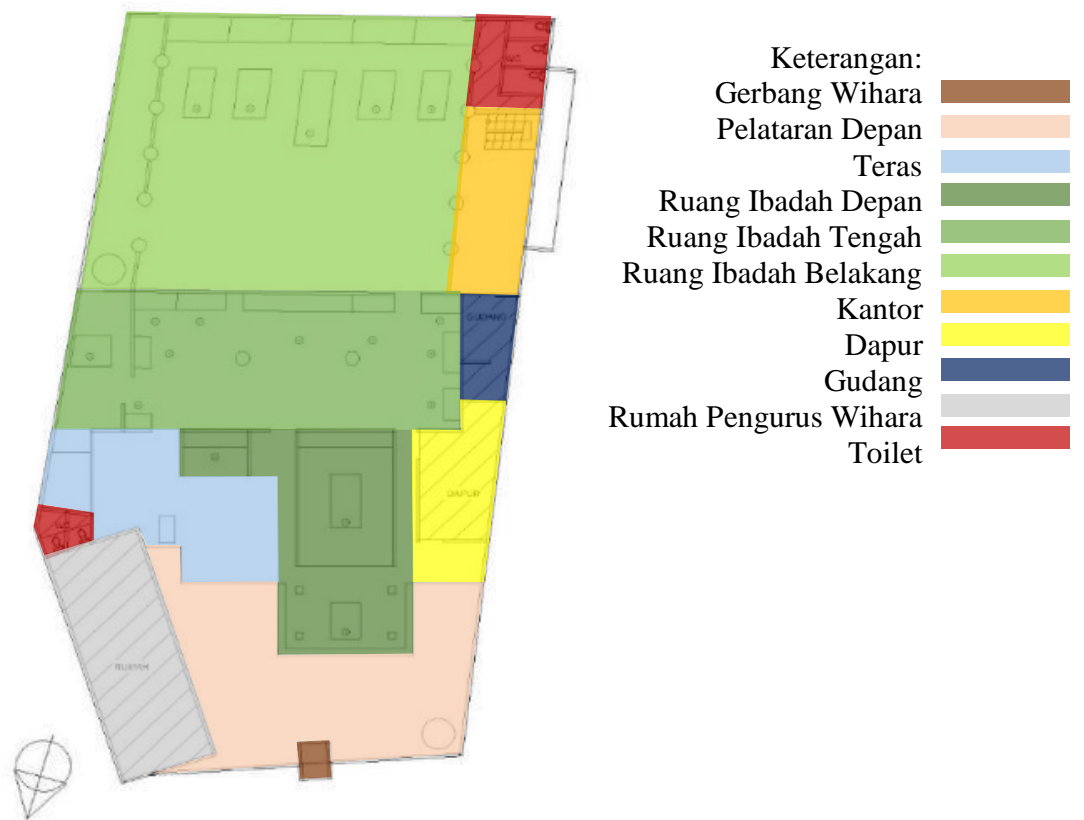

Gambar 2.4 Denah dan Pembagian Ruang Wihara Pemancar Keselamatan Cirebon

Sumber: Data survey lapangan tanggal 1 Maret 2019 
Di Wihara Pemancar Keselamatan terdapat berbagai ruangan yang memiliki fungsi masing-masing. Beberapa ruangan utama (primer) yang tidak bisa dipisahkan dari fungsi wihara yaitu ruang ibadah, namun ada juga ruangan yang berperan sebagai penunjang wihara yang apabila ditiadakan tidak berpengaruh pada fungsi wihara, contohnya kantor pengurus.

Tabel 2 Kategori Ruang di Wihara Pemancar Keselamatan

\begin{tabular}{ccc}
\hline \multicolumn{2}{c}{ Nama Ruang } & Kategori Ruang \\
\cline { 2 - 3 } Ruang Ibadah & Depan & Ruang Primer \\
& & \\
\hline Rengah & Belakang & Ruang Sekunder \\
\hline Kantor Pengurus Wihara & & \\
\hline Toilet Wihara & & \\
\hline Dapur & & \\
\hline Teras & & \\
\hline Gudang &
\end{tabular}

\subsection{Alur Sembahyang di Wihara Pemancar Keselamatan}

Dalam prosesi sembahyang, umat Buddha di Wihara Pemancar Keselamatan memiliki alur dalam peyembahan dewa - dewi. Pengamatan pada prosesi sembahyang bertujuan untuk mengetahui alur pembagian dan hierarki ruang pada tepat ibadah.

Langkah awal sebelum memulai sembahyang adalah jemaah menggambil Hnio ${ }^{5}$ dan lilin yang telah dipaketkan oleh pengurus wihara. Untuk mempermudah jemaah yang sembahyang, terdapat angka pada papan nama Dewa yang menunjukkan nomor urutan sembahyang.

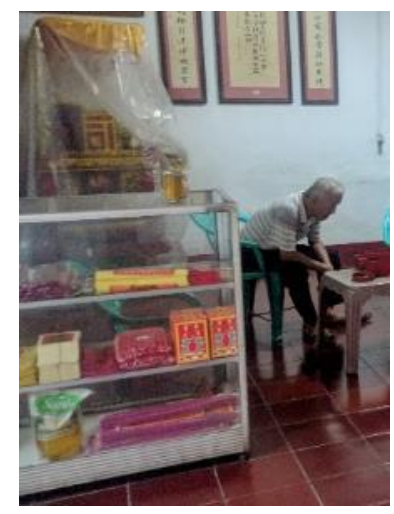

Gambar 2.5 Tempat mengambil Hnio

(Sumber: Data survey lapangan tanggal 1 Maret 2019)

Sembahyang dimulai dari Ruang Ibadah Depan. Dewa yang pertama disembah ialah, Dewa Langit. Kepada Dewa Langit, jemaah menyalakan lilin sekaligus menancapkan tiga Hnio besar di tungku dewa. Kemudian, dilanjutkan ke altar Dewa Bumi dan jemaah dapat membuang sial kepada Dewa Macan yang berada di bawah altar Dewa Bumi. Setelah selesai sembahyang di Ruang Ibadah Depan, jemaah berpindah ke altar yang ada di sebelah kiri, yaitu altar Buddha.

\footnotetext{
${ }^{5}$ Hnio atau Hio adalah dupa yang digunanakan oleh masyarakat Tionghoa sebagai pelengkap ritual ibadah. 


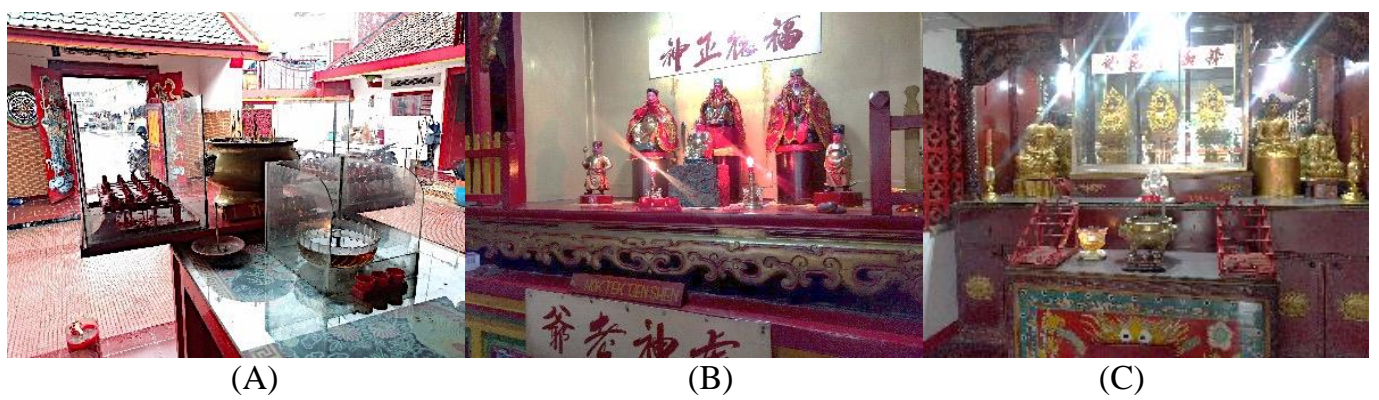

Gambar 2.6 (A) Altar Dewa Langit, (B) Altar Dewa Bumi, (C), Altar Buddha (Sumber: Data survey lapangan tanggal 1 Maret 2019)

Setelah selesai sembahyang di bagian depan, jemaah melanjutkan ibadah ke Ruang Ibadah Tengah. Di ruang Ibadah tengah, jemaah sembahyang kepada Dewi Welas Asih (Dewi Kuan Im) diikuti dengan dewa lainnya.

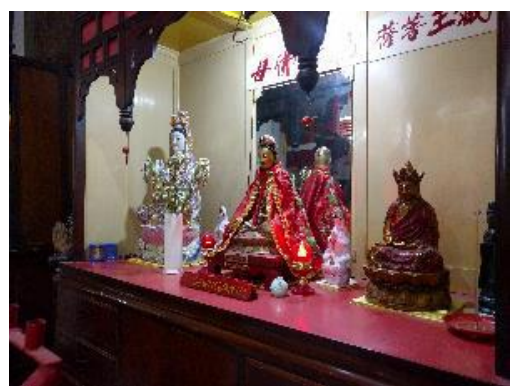

Gambar 2.7 Altar Dewi Kuan Im

(Sumber: Data survey lapangan tanggal 1 Maret 2019)

Kemudian, sembahyang dilanjutkan ke ruang sebelah kiri dari ruang ibadah tengah. Pada ruang tersebut terdapat altar Dewi Pek Khu sebelum wihara diperluas. Di altar tersebut tidak ada rupang Dewi Pek Khu, hanya berupa papan kaligrafi. Setelah diperluas, rupang Dewi Pek Khu dipindah ke Ruang Ibadah Belakang.

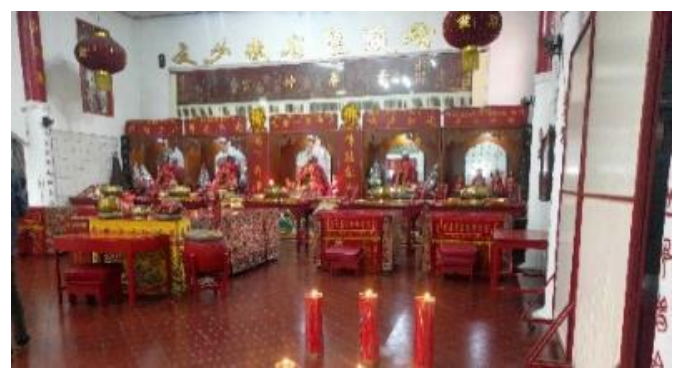

Gambar 2.8 Altar Dewi Pek Khu

(Sumber: Data survey lapangan tanggal 1 Maret 2019)

Terakhir, jemaah sembahyang di ruang ibadah belakang yang merupakan lokasi rupang-rupang Dewi Pek Khu setelah Wihara selesai diperbesar. Disebelah rupang Dewi Pek Khu, terdapat jelangkung yang menuliskan nasihat/jimat. Setelah selesai sembahyang, jemaah membakar kertas kuning di tungku dalam atau tungku luar.

\section{ANALISIS}

\subsection{Hierarki Ruang Ibadah}

Bagian paling depan dari Wihara merupakan altar Dewa Langit (Thie Kong). Dewa Langit merupakan dewa yang disembah pertama kali pada ritual ibadah. Pada ibadah kepada Dewa Langit, jemaah harus mengahap atau melihat langit, sehingga posisi berdoa jemaah berada di dalam bangunan yang menghadap ke langit. Selain itu, posisi altar Dewa Langit berada di sumbu bangunan. Posisi tengah atau sumbu bangunan menurut fengsui ialah posisi yang netral dan seimbang, sehingga dewa-dewa dengan tingkat atau hierarki tertinggi berada di tengah atau di sumbu bangunan. 
Kemudian, jemaah berpindah ke altar Dewa Bumi. Posisi altar Dewa Bumi sejajar dengan Dewa Langit yaitu berada di sumbu bangunan namun peletakkannya agak masuk ke dalam wihara. Seletah selesai berdoa kepada Dewa Langit dan Dewa Bumi, dilanjutkan dengan berdoa di altar Buddha yang berada di sayap kiri dari altar Dewa Bumi.

Setelah ibadah pada bagian depan wihara selesai, jemaah melanjutkan sembahyang ke ruang ibadah tengah. Pada ruang ibadah tengah, dewa yang memiliki hierarki tertinggi ialah Dewi Kwan Im. Maka dari itu, posisi altar Dewi Kwan Im berada di bagian tengah dan belakang ruang ibadah tengah. Menurut tingkatannya posisi altar yang berada di bagian tengah dan terdalam wihara ditempati oleh dewa yang hierarkinya paling tinggi. Selain ditandai dengan posisi peletakkan altar, dewa yang hierarkinya paling tinggi menempati altar yang bentuknya paling megah. Lalu, dewa-dewa yang tingkatannya lebih rendah daripada Dewi Kwan Im, berada di sebelah kiri dan kanan altar Dewi Kwan Im. Posisi dewa yang berada di sebelah kiri altar Dewi Kwan Im memiliki hierarki yang lebih tinggi daripada dewa yang berada di sebelah kanan Dewi Kwan Im.

Di sebelah kiri ruang ibadah tengah, terdapat ruang altar dewi Pek Khu. Dewi Pek Khu merupakan dewi utama dari Wihara Pemancar Keselamatan. Setelah terjadi penambahan ruang di bagian belakang wihara, ruangan tersebut ditempati oleh altar rupang Dewi Pek Khu beserta para ajudannya. Posisi altar rupang Dewi Pek Khu berada di Sumbu Bangunan, kemudian ajudannya berada di sebelah kiri dan kanannya.

\title{
3.2 Sirkulasi
}

Sirkulasi yang terjadi di Wihara Pemancar Keselamatan berpola linier. Sirkulasi pada wihara menggunakan arah linier yang dimulai dari sumbu bangunan atau bagian tengah bangunan. Menurut fengsui bagian tengah merupakan bagian yang netral, seimbang, dan baik. Kemudian dilanjutkan ke arah kiri dan kanan, bagian kiri lebih diutamakan daripada kanan. Dilihat pada Gambar 4.1 karena posisi ruang yang ada pada Wihara Pemancar Keselamatan, terjadi persingungan sirkulasi (cross circulation) pada ruang ibadah tengah.

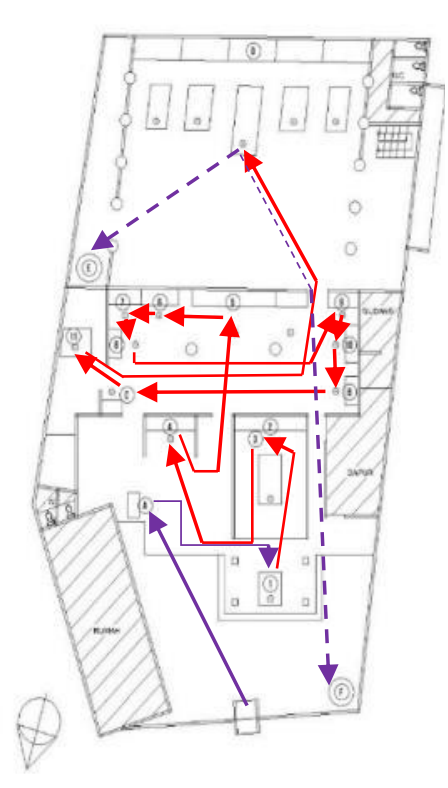

\author{
Keterangan: \\ 1. Dewa Langit (Thie Kong) \\ 2. Dewa Bumi (Hok Tek \\ Tjen Shen) \\ 3. Dewa Macan \\ 4. Buddha \\ 5. Dewi Welas Asih (Dewi \\ Kwan Im) \\ 6. Kwan Thie Kong \\ 7. Nam Pek Taw \\ 8. Pat Lu Tjay Shen \\ 9. Sun Thian Shen Mu \\ 10. Thian How Shen Mu \\ 11. Tjit Shen Kiun \\ A. Tempat mengambil Hnio \\ B. Fuk Fong Tay Ti \\ C. Fuk Lu Su \\ D. Dewi Pek Ku Thay Fuo \\ E. Tungku Dalam \\ F. Tungku Luar
}

\section{Gambar 3.1 Pemetaan Alur Sembahyang Di Wihara Pemancar Keselamatan}

Sumber: Data survey lapangan tanggal 1 Maret 2019 


\subsection{Tata Letak dan Orentasi Massa Bangunan}

Wihara Pemancar Keselamatan berada di posisi "tusuk sate", yaitu di persimpangan antara Jalan Winaon, Jalan Kanoman dan Jalan Keponpiring. Lokasi "tusuk sate" pada fengsui dinilai sebagai lokasi yang memiliki sha ch 'i (energi buruk) yang dapat mengundang nasib buruk. Pembangunan wihara pada lokasi "tusuk sate" ini dapat bertujuan sebagai penangkal sha ch'i agar masyarakat di sekitarnya tidak terganggu kehidupannya.

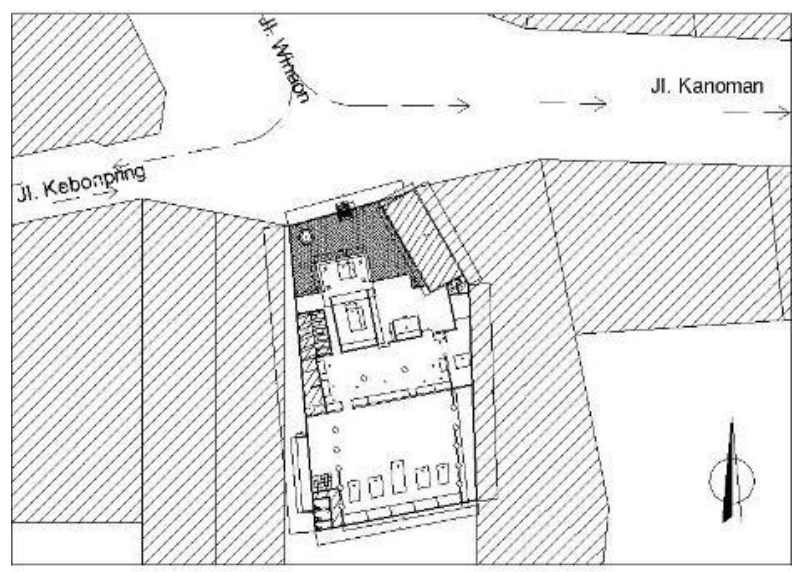

Gambar 3.2 Posisi Wihara Berada di Posisi Tusuk Sate Sumber: Data Survey tanggal 1 Maret 2019

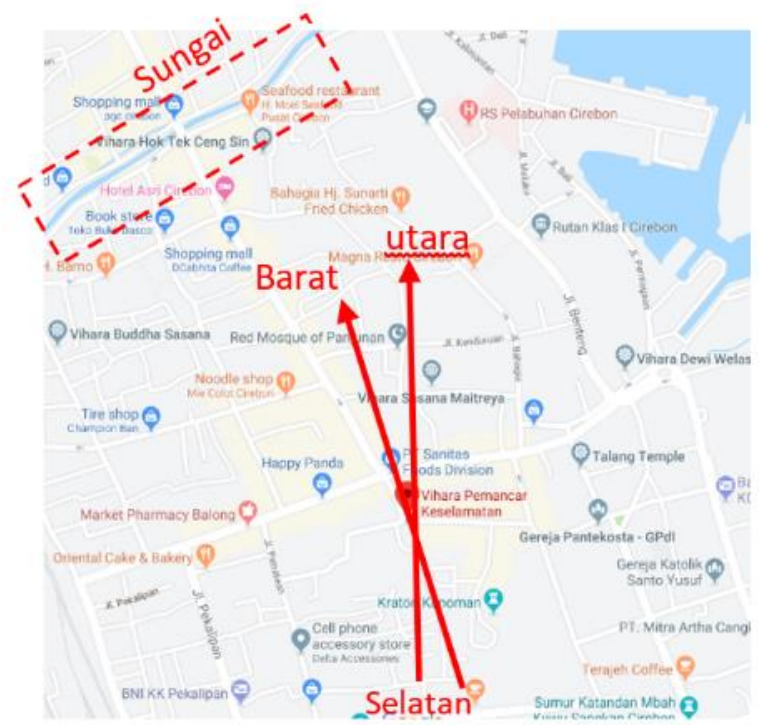

Gambar 3.3 Orientasi Bangunan Wihara Pemancar Keselamatan Cirebon

Sumber: Google Maps, diakses tanggal 23 Mei 2019

Berdasarkan gambar 3.3, massa Wihara Pemancar Keselamatan menghadap ke Barat Laut. Barat Laut bukan merupakan arah yang lazim digunakan pada wihara/kelenteng. Arah yang baik menurut fengsui adalah menghadap ke arah selatan atau menghadap ke arah laut atau sungai dan membelakangi gunung, bukit atau bangunan besar. Namun, tujuan dari pembangunan vihara sebagai penyerap dan penetral sha ch'i (energi buruk) lebih utama, daripada mengikuti arah ideal menurut fengsui. 


\section{SIMPULAN}

Pengaruh fengsui pada hierarki ruang ibadah di Wihara Pemancar keselamatan sangat penting, karena terdapat berbagai macam aturan yang harus ditaati. Aturan ini sangat memengaruhi posisi penempatan altar dewa-dewa dn berhubungan langsung dengan alur ibadah jemaah Wihara Pemancar Keselamatan. Dimulai dari bagian depan dan sumbu bangunan, hingga penempatan altar dewa yang memiliki hierarki yang tertinggi hingga yang lebih rendah.

Selain itu, posisi tata massa dan orientasi bangunan juga sangat dipengaruhi oleh fengsui. Letak Wihara Pemancar Keselamatan berada di posisi tusuk sate yang berfungsi untuk menyerap energi buruk agar energi tersebut tidak membawa nasib buruk kepada masyarakat di sekitar. Meskipun Wihara Pemancar Keselamatan tidak terletak di posisi yang menurut fengsui, fungsi wihara sebagai penetral energi buruk dinilai lebih penting.

Berdasarkan analisis yang sudah dilaksanakan, fengsui memang sangat berperan dalam pembangunan dan penetuan posisi ruang pada Wihara. Terdapat nilai-nilai yang harus dipenuhi demi tercapainya kenyamanan secara spiritual, karena fungsi utama dari wihara adalah sebagai tempat ibadah untuk jemaah.

\section{UCAPAN TERIMA KASIH}

Syukur alhamdulilah senantiasa penulis panjatkan kehadirat Allah SWT, yang selalu memberikan nikmat iman, kesehatan dan kekuatan didalam penelitian ini. Salawat serta salam semoga tetap dilimpah curahkan kepada nabi Muhammad SAW, kepada keluarganya, sahabatnya dan kita selaku umatnya.

Dalam pelaksanaan penelitian ini, berkat dukungan dari berbagai pihak yang sangat membantu dalam pelaksanaan survey lapangan sampai dengan proses analisis dan penyusunan penelitian ini, sehingga sudah selayaknya kami mengucapkan banyak terimakasih yang sebesar-besarnya kepada: Pengurus Yayasan Pemancar Keselamatan di Jl.Winaon, No. 26, Pekalipan, Kota Cirebon, Jawa Barat yang telah memberikan informasi data yang dibutuhkan dalam penelitian ini.

Akhirnya kepada Allah SWT jualah senantiasa para penulis berharap semoga pengorbanan dan segala sesuatunya yang dengan ijinNya, penelitian ini dapat selesai dengan maksimal, dan dapat bermanfaat untuk pembaca.

\section{DAFTAR PUSTAKA}

[1] Suliyati, Titiek. 2011.Tradisi Feng Shui pada Kelenteng di Pecinan Semarang. Sabda, Volume 6, Nomor 1, April 2011: 75-87. Jurusan Sejarah Fakultas Ilmu Budaya Universitas Diponegoro.

[2] Shopie, Benedicta Marcella. 2012. Feng Shui pada Tata Letak Massa Bangunan di Kelenteng Sam Poo Kong. Jurnal Arsitektur KOMPOSISI. Universitas Atma Jaya Yogyakarta.

[3] H. S. Wong, Gideon Slamet. 2013. Rumah Hoki: Menurut Pandangan Feng Shui dan Arsitektur. Griya Kreasi.

[4] http://jabar.tribunnews.com/2018/02/16/inilah-perbedaan-antara-klenteng-dan-vihara-yuk-pahamibiar-tak-bingung-lagi? (Penulis Amalia Qhistyana Amsha) (diakses tanggal 20 Mei 2019, pukul 14.24 WIB)

[5] Too, L. 1995. Feng Shui. Jakarta: PT. Elex Media Komputindo, Kelompok Gramedia.

[6] Kustedja, Sugiri. 2014. Konsep ideologi, hierarki, dan keseimbangan, pada elemen arstektur kelenteng tradisional berdenah type si he yuan. Disertasi Doktoral. Universitas Katolik Parahyangan Bandung. 